\section{Le virus du SIDA est un lentivirus}

L'agent étiologique probable du syndrome d'immunodéficience acquise (SIDA) est un rétrovirus d'environ 9200 bases qui a été désigné sous plusieurs noms : $L A V$ (Lymphadenopathy Associated Virus) par l'équipe française de l'Institut Pasteur de Paris [I ]; HTLV III (Humann T-Cell leukemia/Lymphotropic Virus, type III) par l'équipe $d u$ NCI de Bethesda [2]; et ARV (AIDS-Related Virus) par celle de Californie [3].

La terminologie "HTLV III 》 avait été initialement proposée par homologie avec les virus HTLVI et II, respectivement responsables de leucémies humaines intéressant les lymphocytes $T$ et de leucémies à tricholeucocytes. Elle impliquait que ces trois rétrovirus appartenaient à une même famille. Lorsqu'elles furent disponibles, leurs séquences comparées indiquèrent cependant que LAV|HTLV

1. Barré-Sinoussi F, Cherman JC, Rey F, et al. Isolation of a T-Lymphotropic retrovirus from a patient at risk of acquired immune deficiency syndrome (AIDS). Science 1983; $220: 868-70$.

2. Popovic M, Sarngadharan MG, Read E, Gallo RC. Detection, isolation and continuous production of cytopathic retroviruses (HTLV III) from patients with AIDS and pre-AIDS. Science 1984; $224: 497-500$

3. Levy JA, Hoff man AD, Kramer \$. , et al. Isolation of lymphocytopathic retroviruses from San Fransisco patients with AIDS virus. Science 1984; 225 : 840-2.

4. Sonigo P, Alizon M, Staskus $\mathrm{K}$, et al. Nucleotide sequence of the Visna lentivirus: Relationship to the AIDS virus. Cell 1985; $42: 369$ 82.

5. Chiu IM, Yaniv A, Dahlberg JE, et al. Nucleotide evidence for a relationship of AIDS retrovirus to lentiviruses. Nature 1985; 317 : 366-8

$m / s n^{\circ} 8$ decembre 85
III était extrêmement différent des virus $H T L V-I$ et II. Les partisans de la nomenclature " HTLV " firent alors valoir que les trois virus, certes structuralement différents, avaient en commun une propriété fonctionnelle tout-à-fait fondamentale, la * transactivation ". Il s'agit de l'activation de la transcription du génome viral par le produit d'un de ses gènes, entraînant donc une autostimulation de l'expression du génome infectant. Ce phénomène est d'une très grande importance pour expliquer le mécanisme pathogène des virus, mais il pourrait ne pas être caractéristique de la famille HTLV des rétrovirus. Très récemment, l'équipe pasteurienne [4] et une équipe du NCI [5] viennent d'établir les séquences nucléotidiques du génome de trois lentivirus, une famille de virus dont l'aspect et l'organisation génétique connue rappelaient ceux du virus LAV|HTLV III. Les lentivirus sont responsables d'infections chroniques, à évolution extrêmement lente, telles des atteintes neurologiques du mouton (virus du Visna) et de la chèvre ( $C A E V$, ou Caprine Arthritus Encephalitis Virus), ou une anémie infectieuse du cheval (EIAV, ou Equine Infectious Anemia Virus).

La séquence totale de l' $A R N$ du virus de Visna [4] montre que son organisation globale est en effet très proche de celle du virus du SIDA.

La fraction du génome la plus conservée dans tous les rétrovirus est le gène "Pol" qui code pour la transcriptase reverse (polymérase capable de recopier un brin d'ARN en $A D N)$. La comparaison des séquences de ces gènes "Pol" dans le virus LAV|HTLVIII, les lentivirus cités plus haut, les HTLV I et II et divers autres rétrovirus, montre sans ambiguïté que c'est bien aux lentivirus que s'apparente le plus le virus du SIDA. Au point de vue de leur cycle pathogène, lentivirus et LAV|HTLV III partagent la chronicité de l'infection, l'absence de transformation cellulaire et une atteinte très fréquente $d u$ système nerveux central.
Le mécanisme par lequel ces virus échappent aux défenses immunologiques des organismes infectés qui produisent cependant des anticorps pourrait être double: d'une part, la fréquente mutation du gène "env", codant pour la protéine d'enveloppe, est facteur de variabilité antigénique; d'autre part, le génome viral, et donc l'expression des antigènes viraux, demeurent latents dans les cellules sanguines qui disséminent ainsi l'infection malgré la présence d'anticorps. L'activation de l'expression du virus pourrait être la conséquence de la maturation des cellules infectées ou de leur stimulation antigénique.

Il apparaît, en résumé, que le virus LAVIHTLV III est le premier lentivirus humain et qu'il n'appartient pas à la famille des rétrovirus leucémogènes humains HTLV I et II.

A. K.

\section{Insérer un gène à sa place}

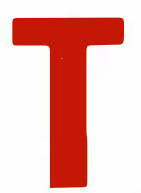

raiter les maladies héréditaires en remplaçant un gène défectueux ou absent représente un objectif qui, s'il reste probablement éloigné, a quitté depuis quelques années le domaine de la science-fiction.

L'utilisation récente des vecteurs rétroviraux pour intégrer un gène étranger dans l'ADN d'une cellule a beaucoup augmenté les espoirs d'un succès dans ce domaine. Le cycle normal des rétrovirus consiste en effet à s'intégrer dans le génome des cellules infectées de telle sorte qu'un vecteur, avant conservé cette pro-

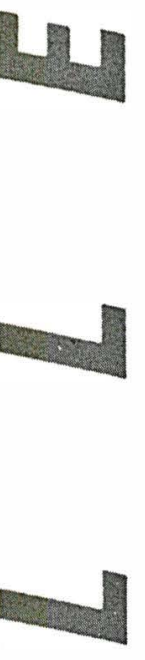
(n)
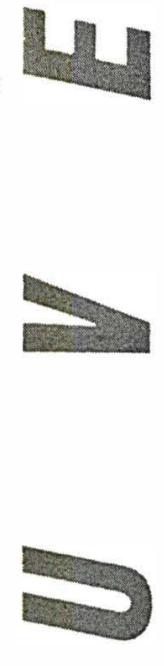

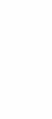

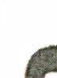

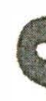

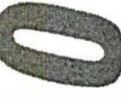

